\title{
Some Characteristics of Background Aerosols Over the Pacific Ocean
}

\author{
By Hiroshi Kojima and Toshio Sekikawa \\ Faculty of Science, Science University of Tokyo. Tokyo. \\ (Manuscript received 6 June 1974, in revised form 29 August 1974)
}

\begin{abstract}
Measurements of the total aerosol concentration and the size distribution of large particles have been performed over the North and South Pacific ocean from November 18, 1971 to March 10, 1972. It was found that the concentration was about $300 \mathrm{~cm}^{-3}$ on an average over the South-Pacific and $450 \mathrm{~cm}^{-3}$ over the North Pacific. Both the concentration and the size distribution of large particles depended on the wind force and showed a pronounced peak around $0.4 \times 10^{-4} \mathrm{~cm}$ in radius.
\end{abstract}

\section{Introduction}

It has been attracting the interest of many researchers to measure the background aerosols which are not directly influenced by continental contamination. The research for those background aerosols will make it possible to make clear the mechanism of the transportation of contaminated air from land to the ocean, and that of the source and sink of aerosols over the ocean, and to predict the climatic variation on the global scale by atmospheric pollution.

The measurements of aerosols in the oceanic atmosphere have been carried out by using several apparatus. Using the Aitken or photo-electric nuclei counter (Pollak counter or Gardner counter), Hess (1951) and Hogan (1967) obtained the total aerosol concentration over the Atlantic. Further the similar measurements were made by Ohta (1951) and Ohta and Ito (1973) over the Pacific and Colacino and Dalu (1972) over the Mediterranean respectively. Using the Gerdien type ion counter, Gunn (1964), Cobb $(1970,1973)$ and Misaki and Takeuchi (1970) have discussed the atmospheric pollution by aerosol particles over the ocean from the concentration of small ions or electrical conductivity. Hitherto it has been said that the latter measuring method is good for the purpose of such as secular variation. Cobb carried out the comparison of electrical conductivity over the South and North Atlantic, and found secular decrease of conductivity over the
Atlantic by the increase of aerosols. The extension of land pollution to the atmosphere over the ocean has studied by Sagalyn (1958), Misaki et al. (1972) and Morita et al. (1973). The ionization equilibrium over the ocean atmosphere has discussed by O'Conner and Sharkey (1968) and Shimo et al. (1972). Junge and Jaenicke (1971) attempted to obtain the aerosol size distribution over a wide size range in the atmosphere over the Atlantic by using several instruments jointly and discussed the background aerosols.

From the results of the above researchers, it was found that the concentration of aerosols in the atmosphere over the Atlantic is higher than that over other oceans, pollution covering a wide range, and that the background value on the ocean of total aerosol is about $300 \mathrm{~cm}^{-3}$. But we think that there are no generalized theory on the relation between the source and sink and the meteorological factors, on the mechanisms of the aerosols extending from land to the ocean, on the secular variations on the global scale. The aim of the present oceanographical survey was to obtain information on the characteristics and source of aerosols in the oceanic atmosphere. Particularly, measurements in the Southern Hemisphere where the data are scarce will be useful. Thereupon, the measurements were made on total aerosol concentration (Condensation nuclei) and on the concentration and size distribution of large particles in the range from 0.15 to $1.5 \times 10^{-4} \mathrm{~cm}$ in radius over the North and South Pacific. The 
data were analyzed from a point of a view of comparing the total aerosol concentration in both hemispheres and of determining the types of size distribution of large particles, and the dependence of the concentration of the large particles and of the total aerosols on wind speed. On the basis of the results we discussed the origin of aerosols in the oceanic atmosphere.

\section{Apparatus}

Generally the concentration of liquid or solid aerosols larger than $10^{-7} \mathrm{~cm}$ in radius has been obtained by means of the particle counter of Pollak type (Pollak and O'Conner 1955). But the counter of this type may not be suitable for obtaining information on the concentration over the ocean because of too low concentration. We developed the following particle counter which was improved on the sensitivity. The diagram of the apparatus is shown in Fig. 1. It consists

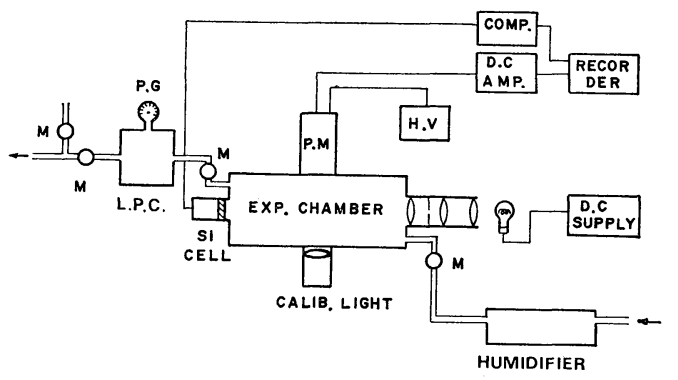

Fig. 1. Schematic diagram of the particle counter.

mainly of the expansion chamber, humidifier, low pressure chamber, light sources, photo-multiplier tube (P.M.T.), D.C. amplifier and so on. The expansion chamber has a capacity of 2.5 liters $(100 \mathrm{~mm}$ in height, $100 \mathrm{~mm}$ in width and $250 \mathrm{~mm}$ in length) and a windows made of acryl resin on each side. The light irradiated from the tungsten lamp is adjusted into parallel beams of about $1 \mathrm{~cm}$ in diameter through the lenses, diaphragms and so on, and enters the chamber. Opposite to the light beams a silicon photocell is set to record the variation of the intensity of the light source. The P.M.T. set at right angles to the incident beams receives only the light scattered by the fog drops produced in the chamber, and changes light beams to electric currents. Opposite to the P.M.T. the lamp which irradiates the light of certain intensity (calibration light) for a short time before adiabatic expansion is prepared for watching the variation of high voltage supplied to the P.M.T. The low pressure chamber (L.P.C.) with pressure gauge has the function of suddenly dropping the pressure in the expansion ratio of 1.21.

The operation is as follows:

A) The open air is introduced through the humidifier chamber into the expansion chamber.

B) Calibration light is irradiated for about five seconds.

C) The pressure in the low pressure chamber is lowered to a certain pressure.

D) The valve between the expansion and the low pressure chamber is opened so suddenly that fog drops are produced on aerosols by adiabatic change.

E) The light scattered by fog drops is converted into the currents $(\mu \mathrm{A})$ by the P.M.T. and the currents are read. Also the currents from the photocell are read and are used to check the intensity of light source.

The operations are automatically worked by timers, relays, electromagnetic valves (M) and so on. The time required for one run is about 5 minutes. As our method is indirect, it is necessary to compare the result with the absolute value which is obtained by the direct method (Kojima 1973). The magnesium oxide (MgO) method was used for detecting the fog drops over the size range from 2 to $10 \times 10^{-4} \mathrm{~cm}$ in radius in the expansion chamber. A film of $\mathrm{MgO}$ was laid by burning magnesium metal on the cover glass. If

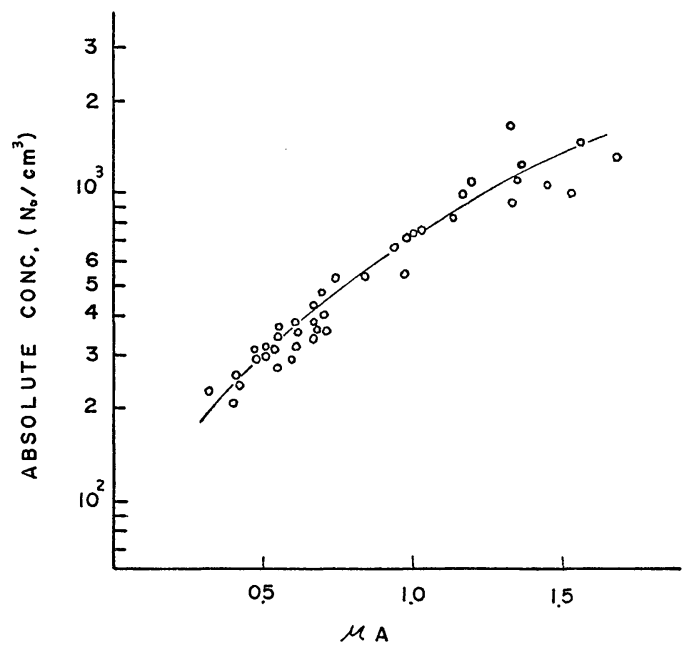

Fig. 2. The calibration curve for the particle counter. $\mu \mathrm{A}$ is the currents obtained from particle counter. 
the fog drops come into contact with the film, the transparent circular traces will remain on the cover glass. The cover glass was put at the bottom of an absolute counter. The expansion chamber of the absolute counter is box-type and the dimentions are $10 \mathrm{~mm}$ in height, $200 \mathrm{~mm}$ in depth and $200 \mathrm{~mm}$ in width respectively. It was taken out of the chamber after the falling of all the fog drops and was examined with a light microscope. The calibration curve obtained from simultaneous measurements of the particle counter and the absolute counter is shown in Fig. 2.

Both size and the concentration of particles larger than $0.15 \times 10^{-4} \mathrm{~cm}$ in radius can be obtained by using the Royco particle counter (Model 202), which is convenient for obtaining data of low concentration as in the oceanic atmosphere, because it has a system by which the scattered light of each particle is detected by P.M.T.

\section{The total aerosol concentration}

Using ships as a platform to carry out the measurement of aerosols over the ocean, we must eliminate the contributions of contamination arising from the chimneys and exhaust ports on the ship. Previously, for determining the position of an intake of sample air, the total aerosol concentration with wind direction and speed was measured by using the portable counter at several places on the ship. On the contamination arising from the ship, Misaki and Takeuchi (1970) and Moyers et al.(1972) has been described in detail. From our data and reports mentioned above it was known that the air passing over the ship is contaminated regardless of the wind speed. Our apparatus was set in the cabin behind the main bridge, where is about 12 meters above the sea surface. The intake of air was pushed out on

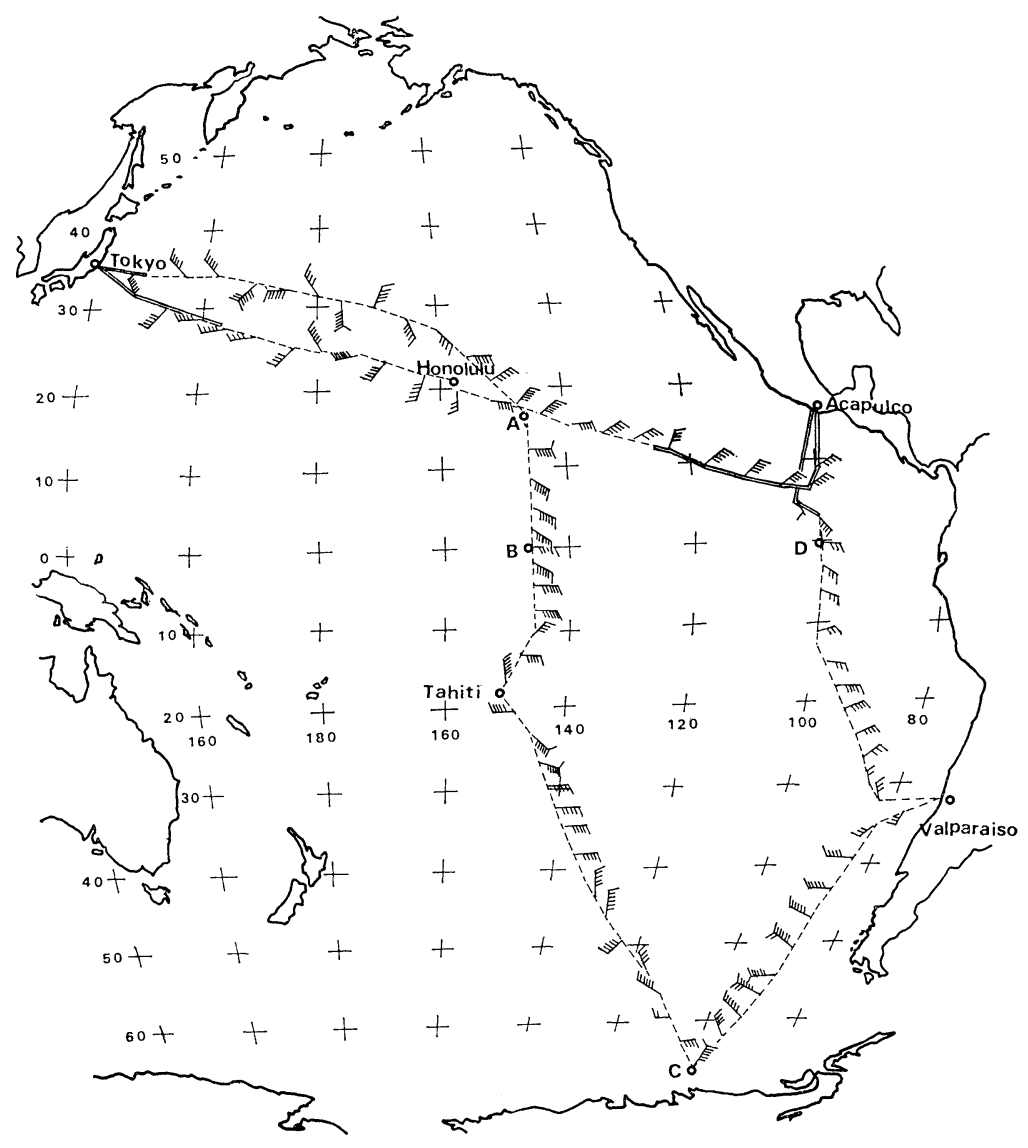

Fig. 3. The routes and prevailing wind direction during our expedition. 
the open sea and moved along the right or left side to the bow as it was to the windward of the ship. For another contamination source, the ship while sailing forms a white-cap and some aerosols may be produced by white-cap effect. Since it is necessary to estimate its effect, measurements were carried out during both sailing and drifting. It was concluded from a statistical comparison of the data during sailing and drifting that the effects can be neglected.

The route map and the prevailing winds during our expedition are shown in Fig. 3. Parallel solid lines indicate total aerosols concentration in more than $800 \mathrm{~cm}^{-3}$. The data of the total aerosols concentration along latitude and longitude are illustrated in Fig. 4. The observed value at noon
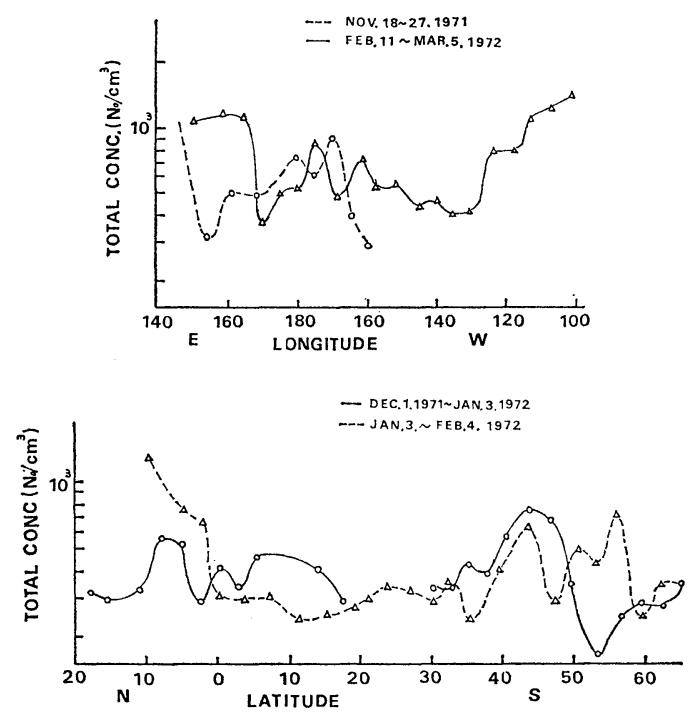

Fig. 4. The variation of the total aerosols along longitude and latitude.

by the local standard time (L.S.T.) was adopted for each day, which means that we have every one at intervals of about $300 \mathrm{~km}$. By the seasonal northwest wind near Tokyo and the northeast trade wind near North America, our data were directly received the influence of land contamination. It is found that continental influences are still present about $2000 \mathrm{~km}$ off-shore west of North America.

The frequency distributions of background aerosols over the South and North Pacific, and the mean value and standard deviation of each leg are shown in Fig. 5. In order to estimate background values of aerosols, we omitted those

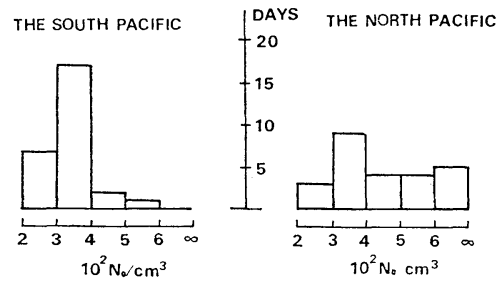

\begin{tabular}{|c|c|c|c|c|c|}
\hline \multicolumn{2}{|r|}{ LEG } & & $\begin{array}{c}\text { TOIAL CONC } \\
\mathrm{N}_{6} / \mathrm{cm}^{3}\end{array}$ & \multicolumn{2}{|c|}{\begin{tabular}{|l|} 
LARGE PARTICLEE \\
$0.2 \sim 0.5 \mu \mid 0.6 \sim 1.0 \mu$ \\
\end{tabular}} \\
\hline (1) & TоКYО $\rightarrow$ B & $\mathbf{N}$ & $410 \pm 29$ & 3.2 & 1.1 \\
\hline (1) & $A \longrightarrow B$ & $\mathbf{N}$ & $334 \pm 24$ & & \\
\hline (2) & $\mathrm{B} \rightarrow \mathrm{C} \rightarrow$ VALPARAISO & $\mathbf{s}$ & $344 \pm 10$ & 5.7 & 1.5 \\
\hline (3) & VALPARAISO $\rightarrow$ D & $\mathbf{s}$ & $293 \pm 9$ & 0.97 & 0.14 \\
\hline (4) & ACAPULCO $\rightarrow$ TOKYO & $\mathbf{N}$ & $484 \pm 28$ & 2.3 & 0.58 \\
\hline
\end{tabular}

Fig. 5. The frequency distribution of background aerosols over the South and North Pacific, and the mean value and standard deviation of each leg. $N$ and $S$ of the third parenthesis indicate the Northern and the Southern Hemisphere, respectively.

data obtained less than $2000 \mathrm{~km}$ away from the land on the Northern Hemisphere and those in bad weather such as raining or complete cloudiness. The frequency distribution over the South Pacific shows a median concentration of about $300 \mathrm{~cm}^{-3}$ and more than $80 \%$ of total data is contained from 200 to $400 \mathrm{~cm}^{-3}$. The values are very similar to those reported by other researchers. On the other hand, the mode over the North Pacific is the same as the former but the distribution is such a broad type that a concentration more than $600 \mathrm{~cm}^{-3}$ exists. Going south down the center of the North Pacific (leg $1^{\prime}$ ), the mean value is less than one of other legs on the North Pacific and is almost the same as the one over the South Pacific. The present data show that the atmosphere over the Northern Hemisphere is polluted more than that in the Southern Hemisphere.

The mean value in leg (2) containing a storm zone is much larger than that in leg (3), where the wind speed was very weak. As the reason for this it is suggested that the total aerosol concentration may depend on the wind speed. The relation between the total aerosol concentration and wind force over the South Pacific is shown in Fig. 6.

In spite of the dispersion of the data, Fig. 6 suggests that there may be positive correlation. 


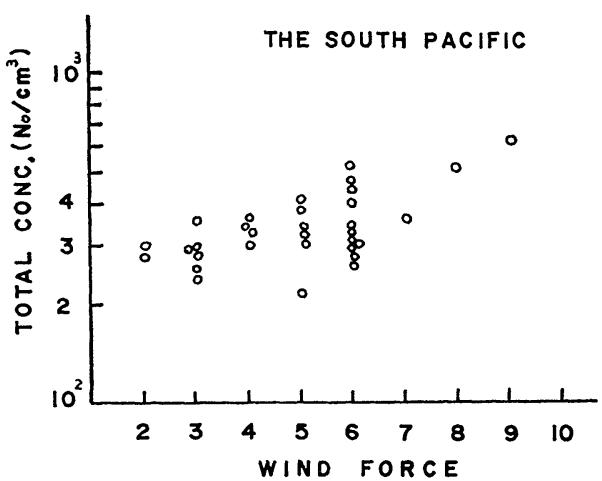

Fig. 6. The dependence of particles on the wind force (Beaufort)

However, over the North Pacific the correlation could not be distinguished. The reason for this is supposed to be that over the North Pacific a region of high background exists in part and that during our survey the variation of wind force was small. Production of fine particles from the sea surface can be considered but this is not main source over the ocean.

Colacino and Dalu (1972) have reported that the concentration of total aerosols depends on the wind speed. Our data seem to support his result. Ohta (1951) has reported that the mean value over the North Pacific is about $290 \mathrm{~cm}^{-3}$. The value is comparable with that of our leg (2). The concentration of the total aerosols over the Atlantic reported by Hess, Hogan and Junge is much more than our values.

\section{Large particles}

The measurements of large particles were carried out three times in a day (at $9^{\mathrm{h}}, 12^{\mathrm{h}}$, and $18^{\mathrm{h}}$ of L.S.T). If the concentration is free from contamination, it will heavily depend on wind force, increasing as the latter increases. This is proved by a comparison of mean values in leg (2) and leg (3) in Fig. 5. The size distributions classified by wind force are presented in Fig. 7. The bars indicate a standard deviation and the number of data per each wind force is from 5 to 13. Junge (1955) showed for continental aerosols that the size distribution of large particles obeys always the following formula:

$$
\frac{d N}{d \log r}=A r^{-B},
$$

where $A$ is constant, $B$ is about $3, r$ is the particle radius and $N$ is the concentration. The formula

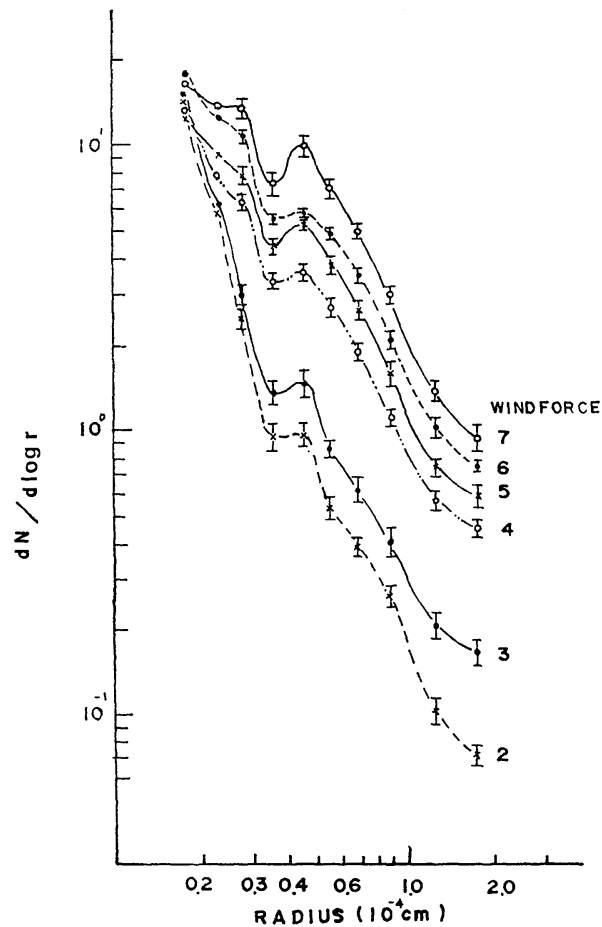

Fig. 7. The size distributions classified by wind force. Bars indicate standard deviations.

has proved by many researchers theoretically and experimentally (e.g. Friedlander 1960). From Fig. $7, B$ is smaller than the value on the land. Junge and Jaenicke (1971) has reported that using the Royco counter and a set of five double stage impactors they measured the size distribution of aerosols over the Atlantic and $B$ equals 3 as over the land.

Size distributions of large particle depend remarkably on the wind force in size range larger than about $0.2 \times 10^{-4} \mathrm{~cm}$ in radius. In size ranges smaller than about $0.2 \times 10^{-4} \mathrm{~cm}$ the dependence of the concentration of particles on the wind force becomes unclear. It has recognized that if the concentration of particles depends on the wind force, the particle will be that produced from the sea surface. From the present data particles larger than $0.2 \times 10^{-4} \mathrm{~cm}$ seem to be produced from the sea. Our results upon the dependence the particles on wind force are similar to those of Woodcock (1953), who measured the relation between wind force and the mass distribution of sea salt particles in the size range from 2.4 to $51 \times 10^{-4} \mathrm{~cm}$ in radius.

It is a notable result that a peak appears in 


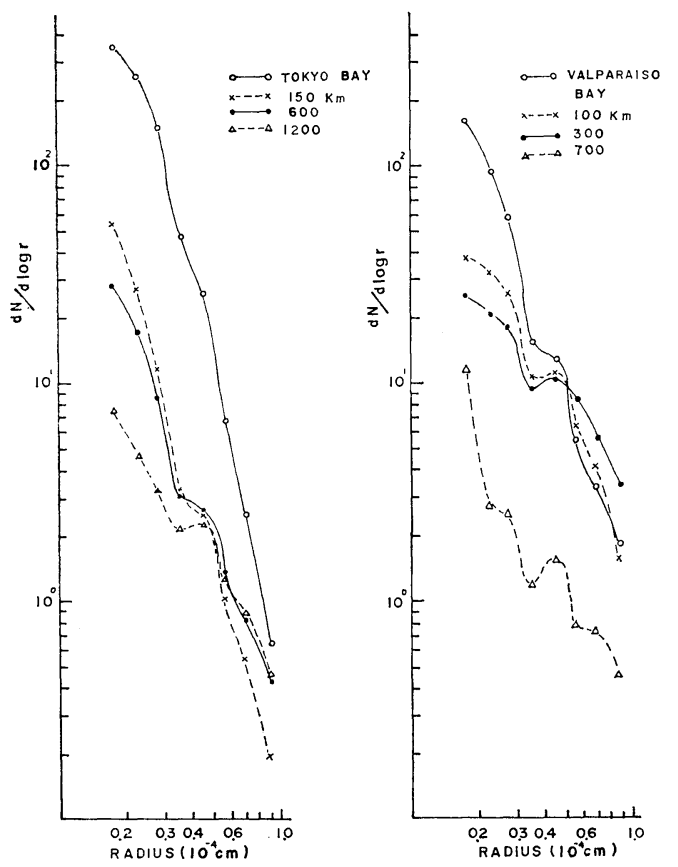

Fig. 8. The variation of the size distributions of large particles with distance from the land.

the vicinity of $0.4 \times 10^{-4} \mathrm{~cm}$ on every curve. The peak disappears with the approaching of land (Fig. 8). Pueschel et al. (1969) has reported that a peak in the vicinity of $0.4 \times 10^{-4} \mathrm{~cm}$ in radius appeared in the size distribution of sea spray aerosols from the measurement at the sea-coast. It may be interpreted that in the distribution in Fig. 7 the land size distribution is superposed upon that of particles of oceanic origin which has a peak around $0.4 \times 10^{-4} \mathrm{~cm}$.

\section{Results and Discussion}

1) The influence of continental contamination extends at times to $2000 \mathrm{~km}$ and more away over the ocean, where there is a large city near the coast. We do not attempt in this paper a detailed discussion on the long-range transport of aerosols from man-made sources.

2) The total aerosols concentration showed an average around $300 \mathrm{~cm}^{-3}$ over the South Pacific while around $450 \mathrm{~cm}^{-3}$ over the North Pacific. The values over the South Pacific points to the absence there of any contamination due to man-made sources and the values over the North Pacific seem to be less than those over the North Atlantic. For detecting the aerosol particles both methods, $i$. $e$. measurement of electrical conductivity and of condensation nuclei, have been carried out by many researchers. Both suffer from some unavoidable defects (Cobb, 1973) (Hogan et al, 1973). We think that measurement of conductivity suits for secular variations and that measurement of condensation nuclei for a discussion of the mechanism of source and sink of aerosols since this affords data in all kinds of weather.

3) The concentration of large particles depends on the wind force, particularly in size range larger than $0.2 \times 10^{-4} \mathrm{~cm}$ in radius. Also the size distribution depends on the wind force, and $B$ decreases with increasing wind force. That most of the large particles over the ocean are originated from the ocean surface is supported by the report on the volatility of aerosols (Kojima, 1974).

4) $\mathrm{A}$ peak in the vicinity of $0.4 \times 10^{-4} \mathrm{~cm}$ in radius in size distribution of large particles was obtained. This was measured at every place free from land contamination. It can be inferred that these are the characteristics of the oceanic atmosphere and that aerosols is produced continuously over the ocean surface. As regards the confidence of the sizing oceanic aerosols by Royco Particle counter, we have not examined yet. Therefore, by using the direct method such as the examination with a microscope, we intend to make further the measurements which support the result obtained here.

\section{Aknowledgement}

We wish to express our thanks to professor S. Horibe and the staff of the Ocean Research Institute, University of Tokyo for kindly giving us an opportunity of making our measurements on the research vessel Hakuho-Maru.

\section{References}

Cobb. W. E, and H. J. Wells, 1970: The Electrical conductivity of oceanic air and its correlation to global atmospheric pollution. J. Atmos. Sci. vol. 27, 814-819.

- 1973: Oceanic levels deduced from measurements of the electrical conductivity of the atmosphere. J. Atmos. Sci. 30, 101-106.

Colacino. M, and G. A. Dalu, 1972: Condensation nuclei measurements in marine atmosphere (Mediterranean Sea). Pure and Appl. Geofis vol. 93, 
205-213.

Friedlander, S. K. 1960: Similarity considerations for the particle size spectrum of a coagulating, sedimentating aerosol. J. Meteor. 17, 479-483.

Gunn. R. 1964: The secular increase of the world wide fine particle pollution. J. Atmos. Sci. vol. 21, 168181.

Hess. V. F. 1951: Further determinations of the concentration of condensation nuclei in the air over the North Atlantic. J. G. R. vol. 56, 553-556.

Hogan. A. W. 1967: Aitken nuclei observations over the North Atlantic Ocean. J. Appl. Meteor. vol. 6, 726-727.

- V. A. Mohnen and V. J. Schaefer. 1973: Comments on Oceanic Aerosol Levels Deduced from Measurements of the Electrical Conductivity of the Atmosphere. J. Atmos. Sci. vol. 30, 1455-1460.

Junge, C., 1955: The size distribution and aging of natural aerosols as determined from electrical and optical data. J. Meteor. 19, 13-26.

- 1969: A study of aerosols in pacific air mas J. Appl. Meteor. vol. 8,340-347.

ground aerosols studies from the Atlantic expedition of the R. V. Meteor, spring 1969, J. Aerosol Science. vol. 2, 305-314.

Kojima, H., T, Sekikawa and F, Tanaka, 1974: On the volatility of large particles in the urban and oceanic atmosphere. J. Meteor. Soc. Japan. vol. 52, 90-92.

$\longrightarrow$, and 1973: The problems on measurements of condensation nuclei. Tenki. vol. 20, 300-306.

Misaki, M. and T, Takeuti, 1970: The extension of air pollution from land over ocean revealed in the variation of atmospheric electrical conductivity, $J$. Meteor. Soc. Japan. vol. 48, 263-269.

, and I, Kanazawa, 1972:

Atmospheric electrical conductivity measurement in the Pacific Ocean exploring the background level of global pollution. J. Meteor. Soc. Japan. vol. 50. 497-500.

Morita, Y., H. Ishikawa., J. Nagasawa and M. Kanada, 1973: The land to ocean transitional behavior of the atmospheric electric parameters and their relation to atmospheric pollution. J. Meteor. Soc. Japan. vol. 51, 294-306.

Moyers, L., R. A. Duce, and G. L. Hoffman, 1972: A note on the contamination of atmospheric particulate samples collected from ships. Atmospheric Environment. vol. 6, 551-556.

O'Connor, T. C., and W. P. Sharkey, 1963: Ionization equilibrium in maritime air. Proc. R. I.A. vol. 61, 15-27.

Ohta, S. 1951: On the contents of condensation nuclei and uncharged nuclei on the Pacific Ocean and the Japan Sea. Bull. Am. Meteor. Soc. vol. 32, 30-31.

Ohta, S., and T. Ito, 1973: Method of measurement of the background concentration of submicron aerosols and some results from the observations around the Ogasawara Islands and Marcus Island. Papers in Meteorology and Geophysics. vol. 24, 111-137.

Pollak, L. W. and T. C. O'Connor, 1955: A photoelectric condensation nuclei counter of high precision. Geofis. Pure. e Appl. vol. 32, 139-149.

Pueschel, R. F., R. J. Charlson, and N. C. Ahlquist, 1969: On the anomalous deliquescence of seaspray aerosols. J. Appl. Meteor. vol. 8, 995-998.

Sagalyn, R. C., 1958: The production and removal of small ions and charged nuclei over the Atlantic Ocean. Recent Advances in Atmospheric Electricity Pergamon Press. 21-41.

Shimo, M., Y. Ikebe, T. Nakayama, and M. Kawano, 1972: Measurement of small ions and condensation nuclei over the sea near the land. Pure. Appl. Geophys. vol. 100, 109-122.

Woodcock, A. H., 1953: Salt nuclei in marine air as a function of altitide and wind force. J. Meteor. vol. 10, 362-371.

\title{
太平洋上のバックグラウンドエアロソルの特性
}

\author{
児島紘, 関 川 俊 男 \\ 東京理科大学・理学部
}

1971年11月18日から1972年 3 月10日迄，南北太平洋上で粒子総数と大粒子の粒径分布の測定を行った. その結果, 粒子総数は南太平洋上で約 300 個 $/ \mathrm{cm}^{3}$, 北太平洋上で約 450 個 $/ \mathrm{cm}^{3}$ の平均值であった. 大粒子の濃度と粒径分布は風 力に依存する事がわかった。 そして半径 $0.4 \times 10^{-4} \mathrm{~cm}$ の附近に一つの極大がある事が顕著な結果の一つであった. 